\title{
GAMBARAN PENGETAHUAN TENTANG KESEHATAN GIGI DAN MULUT DENGAN STATUS KEBERSIHAN GIGI DAN MULUT (OHI-S) PADA SISWA SMP DI MAJALENGKA
}

\author{
Anang ${ }^{1}$ \\ ${ }^{1}$ Dental Therapy, Poltekkes Kemenkes Tasikmalaya, Jawa Barat, Indonesia \\ anangbdg76@gmail.com
}

Kata kunci:

Pengtahuan

Kesehatan Gigi dan Mulu Statutus Kebersihan Gigi dan Mulut

\section{ABSTRAK}

Tujuan dari penelitian ini adalah untuk mengetahui tingkat pengetahuan tentang kesehatan gigi dan mulut pada siswa kelas VII SMPN 1 Lemahsugih. Jenis penelitian ini adalah penelitian observasional dengan rancangan penelitian menggunakan metode deskriftif. Populasi penelitian ini adalah kelas VII SMPN 1 Lemahsugih Kabupaten Majalengka yang berjumlah 101 siswa. Sampel terdiri dari bagian populasi terjangkau yang dapat dipergunakan sebagai subjek penelitian melalui Sampling. Sampel yang dipilih dalam penelitian ini menggunakaan nonprobability sampling. Besar sampel yang akan digunakan dalam penelitian ini sejumlah 33 orang. Teknik pengumpulan data menggunakan kusioner untuk pengetahuan kesehatan gigi dan skor OHI-S untuk mengukur OHIS. Analsis data dilakukan dengan cara membuat daftar distrbusi frekuensi. Berdasarkan hasil penelitian tentang "Gambaran pengetahuan tentang kesehatan gigi dan mulut dengan status kebersihan gigi dan mulut pada siswa kelas VII SMPN 1 Lemahsugih Kabupaten Majalengka Tahun 2015", maka dapat disimpulakn sebagai berikut : 1) Tingkat pengetahuan tentang kesehatan gigi dan mulut siswa kelas VII A SMPN 1 Lemahsugih Kabupaten Majalengka, yang mendominasi adalah kategori pengetahuan kategori pengetahuan sedang dengan rentan nilai (6-9) sebanyak 24 orang $(72.8 \%)$, 2) Hasil pemeriksaan Oral Hygiene Index Simplified (OHI-S) siswa kelas VII SMPN 1 Lemahsugih Kabupaten Majalengka, yang mendominasi adalah kategori sedang dengan rentan nilai $(1.3-3.0)$ sebanyak 16 orang $(48.5 \%)$

Key word:

Knowledge

Dental and Oral Health

Statute of Oral and Dental Hygiene

\section{ABSTRACT}

The purpose of this study was to determine the level of knowledge about dental and oral health in grade VII students of SMPN 1 Lemahsugih. This type of research is observational research with a research design using descriptive methods. The population of this study was class VII of SMPN 1 Lemahsugih, Majalengka with a total of 101 students. The sample consists of affordable population parts that can be used as research subjects through sampling. The sample selected in this study uses nonprobability sampling. The number of samples that will be used in this study is 33 people. Data collection techniques used questionnaires for dental health knowledge and OHI-S scores to 
measure OHIS. Data analysis is done by making a list of frequency distributions. Based on the results of research on "The description of knowledge about oral health with dental and oral hygiene status in class VII students of SMPN 1 Lemahsugih Majalengka in 2015", it can be summarized as follows: 1) The level of knowledge about dental and oral health of grade VII A students SMPN 1 Lemahsugih Majalengka, which dominates is the knowledge category of the moderate knowledge category with a vulnerable value (6-9) of 24 people $(72.8 \%), 2)$ Oral Hygiene Index Simplified (OHI-S) examination results of Grade VII students of SMPN 1 Lemahsugih Majalengka, which dominated was the medium category with vulnerable scores (1.3 3.0) of 16 people ( $48.5 \%)$

\section{PENDAHULUAN}

Derajat kesehatan masyarakat dipengaruhi oleh empat faktor utama, yakni: lingkungan, perilaku, pelayanan kesehatan, dan keturuan (herediter). Memelihara dan meningkatkan derajat kesehatan masyarakat harus ditunjukan pada ke empat faktor utama tersebut secara bersama-sama. Perilaku masyarakat tidak siap menerima itu semua, disamping karena fasilitas-fasilitas tersebut tidak sesuai dengan nilai-nilai kebiasaan masyarakat. Kebiasaan masyarakat sesuai dengan nilai-nilai kesehatan maka diperlukan pendidikan atau promosi dibidang kesehatan, sehingga perilaku sehat dalam masyarakat dapat terwujud Notoadmodjo (2010).

Menurut Fitriani (2011), perilaku sehat adalah respon seseorang (organisme) terhadap stimulus (rangsangan) atau objek yang berkaitan dengan sehat dan penyakit, sistem pelayanan kesehatan, makanan dan minuman serta lingkungan. Telah diuraikan diatas bahwa perilaku kesehatan selain dipengaruhi beberapa faktor diatas juga sangat dipengaruhi oleh pengetahuan tentang kesehatan, karena pengetahuan kesehatan sangat penting dalam meningkatkan status kesehatan pada umumnya maupun kesehatan gigi pada khususnya. Cara meningkatan perilaku kesehatan masyarakat adalah dengan cara meningkatkan pengetahuan akan kesehatan itu sendiri.

Menurut Notoatmodjo (2010), pengetahuan adalah hasil pengindraan manusia, atau tahu seseorang terhadap objek melalui indra yang dimilikinya (mata, hidung, telinga, dan sebagainya). Pada waktu pengindraan, sehingga menghasilkan pengetahuan tersebut sangat dipengaruhi oleh intensitas perhatian dan persepsi terhadap objek. Pegetahuan seseorang diperoleh melalui indra pendengaran (telinga), dan indra penglihatan (mata). Pengertian pengetahuan kesehatan hampir sama dengan pengetahuan umum, hanya saja pengetahuan kesehatan lebih terfokus pada bidang kesehatan. Soekanto (2010), mengemukakan bahwa ilmu pengetahuan merupakan pengetahuan yang tersusun secara sistematis dengan penggunaan kekuatan pemikiran, di mana pengetahuan tersebut selalu dapat diperiksa dan ditelaah dengan kritis. Menurut Notoatmodjo (2003) banyak yang dapat digunakan untuk memperoleh pengetahuan, namun sepanjang sejarah cara mendapatkan pengetahuaan dikelompokkan menjadi dua yaitu cara tradisional atau non ilmiah dan cara modern atau yang diebut cara ilmiah.

Pengetahuan sangat erat hubungannya dengan pendidikan, dimana diharapkan bahwa dengan pendidikan yang tinggi maka masyarakat tersebut akan semakin luas pula pengetahuannya. Upaya kesehatan gigi perlu di tinjau dari aspek lingkungan, pengetahuan, 
pendidikan, kesadaran masyarakat dan penanganan kesehatan gigi termasuk pencegahan dan perawatan (PRO HEALTH, 2010). Pendidikan kesehatan gigi dan mulut adalah semua upaya atau aktivitas yang mempengaruhi orang-orang untuk bertingkah laku yang baik bagi kesehatan dan rneningkatkan kesadaran masyarakat akan kesehatan gigi dan mulut serta memberikan pengertian cara-cara memelihara kesehatan gigi dan mulut (Miko, $\mathrm{H}$. and Suminar, L.R., 2017). Penyebab timbulnya masalah kesehatan gigi dan mulut pada masyarakat salah satunya adalah faktor perilaku atau sikap mengabaikan kebersihan gigi dan mulut. Hal tersebut dilandasi oleh kurangnya pengetahuan akan pentingnya pemeliharaan gigi dan mulut. Untuk memperoleh pengetahuan kesehatan, seseorang harus melalui proses pendidikan kesehatan (Notoatmodjo, 2010 Cit., Fankari 2004).

Pendidikan kesehatan menurut Suliha, dkk, (2002), bahwa pendidikan kesehatan merupakan usaha atau kegiatan untuk membantu individu, kelompok, dan masyarakat dalam meningkatkan kemampuan baik pengetahuan, sikap, maupaun keterampilan untuk mencapai hidup sehat secara optimal, memiliki gigi dan mulut yang sehat. Pernyataan ini di dukung oleh pendapat dari Herijulianti, dkk., (2002), bahwa pendidikan kesehatan adalah proses belajar mengajar pada individu atau kelompok masyarakat tentang nilai-nilai kesehatan sehingga mereka mampu mengatasi masalah kesehatan, terutama masalah kesehatan gigi. Faktor yang mempengaruhi kesehatan gigi adalah pendidikan akan kesehatan gigi itu sendiri dimana pendidikan kesehatan gigi adalah semua aktifitas yang membantu menghasilkan penghargaan masyarakat akan kesehatan gigi dan memberikan pengertian akan cara -cara bagaimana memelihara kesehatan gigi dan mulut.

Penyakit gigi dan mulut lebih banyak terdapat dalam kondisi rongga mulut yang kotor. Sebagian besar orang menomorduakan kondisi kesehatan gigi dan mulut (Kompas,2007). Plak atau Debris di permukaan gigi dapat dipakai sebagai indikator kebersihan mulut. Pembersihan gigi yang kurang baik menyebabkan plak mengumpul paling banyak (Dendika Dental Journal, Vol 2 2002). kebanyakan Penyebab masalah kesehatan gigi dan mulut adalah plak. Plak inilah yang menjadi fokus utama dalam menjaga kebersihan gigi dan mulut. Plak memiliki konsentrasi yang lunak sehingga mudah di bersihkan dengan penyikatan gigi yang baik, plak akan tetap terbentuk setelah dibersihkan, karena itu, rutinitas menjaga kebersihan gigi dari plak sangat penting agar plak tidak bertambah banyak dan tebal (Ramadhan, 2010).

Kesehatan gigi dan mulut dapat dipelihara dengan cara-cara menjaga kebersihan gigi dan mulut. Cara untuk meningkatkan kesehatan gigi dan mulut adalah dengan cara mengukur kebersihan gigi dan mulut, mengukur kebersihan gigi dan mulut merupakan upaya untuk menentukan keadaan kebersihan gigi dan mulut seseorang. Pada umumnya untuk mengukur kebersihan gigi dan mulut digunakan suatu indeks. Diantaranya untuk mengukur kebersihan gigi dan mulut seseorang Green and Vermillion menggunakan indeks yang di kenal dengan OHI-S (Oral Hygiene Indexs Simplified), yaitu memilih enam permukaan gigi indeks tertentu yang cukup dapat mewakili segmen depan maupun belakang dari seluruh pemeriksaan gigi yang ada dalam rogga mulut (Putri, dkk., 2010). Kebersihan gigi dan mulut sangatlah penting untuk menunjang kesehatan tubuh secara keseluruhan. Mulut adalah pintu gerbang dari segala makanan dan minuman yang masuk ke dalam tubuh, kesehatan gigi dan mulut dapat berpengaruh secara signifikan terhadap organ-organ lain di dalam tubuh kita (Susanto, GW., 2011)

$O H I-S$ adalah suatu indeks untuk mengukur kebersihan gigi dan mulut seseorang. Green and Vermillion memilih enam permukaan gigi indeks tertentu yang cukup dapat mewakili segmen depan maupun belakang dari seluruh pemeriksaan gigi yang ada dalam rongga mulut (Putri, dkk., 2013). Menurut Herijulianti, dkk., (2002), untuk menilai kebersihan gigi dan mulut seseorang yang dilihat adalah adanya debris dan kalkulus pada 
Home page: http://ejurnal.poltekkestasikmalaya.ac.id/index.php/jikg permukaan gigi. Berdasarkan hasil penelitian yang dilakukan oleh Wilha Tirhana Kowela tahun 2012, yang membahas tentang "Gambaran Pengetahuan Pemeliharaan Kesehatan Gigi dan Mulut Dengan Indeks $O H I-S$ Pada Mahasiswa Tingkat 1 Jurusan Keperawatan Gigi Politeknik Kesehatan Tasikmalaya tahun 2012" dengan kriteria OHI-S sedang $77.5 \%$ (31 orang) dan pengetahuan sedang 67.5\% (27 orang). Tujuan dari penelitian ini adalah mengetahui Gambaran Pengetahuan Dengan Status Kebersihan Gigi dan Mulut Pada Siswa Kelas VII SMPN 1 Lemahsugih Majalengka 2015

\section{METODE}

Jenis penelitian ini adalah penelitian observasional dengan rancangan penelitian menggunakan metode deskriftif. Menurut Setyosari., (2010), metode deskriftif yaitu penelitian yang bertujuan untuk menjelaskan atau medeskripsikan suatu keadaan, atau peristiwa, untuk mengetahui gambaran pengetahuan tentang kesehatan gigi dan mulut dengan $O H I-S$ pada siswa siswi kelas VII SMPN 1 Lemahsugih Kabupaten Majalengka. Populasi penelitian ini adalah kelas VII SMPN 1 Lemahsugih Kabupaten Majalengka yang berjumlah 101 siswa. Sampel terdiri dari bagian populasi terjangkau yang dapat dipergunakan sebagai subjek penelitian melalui Sampling. Sampel yang dipilih dalam penelitian ini menggunakaan nonprobability sampling (Nursalam, 2009). Besar sampel yang akan digunakan dalam penelitian ini sejumlah 33 orang (total sampel) yang diperolah dari buku induk siswa kelas VII A, B, dan C SMPN 1 Lemahsugih Kabupaten Majalengka. Teknik pengumpulan data menggunakan kusioner untuk pengetahuan kesehatan gigi dan skor OHI-S untuk mengukur OHIS. Analsis data dilakukan dengan cara membuat daftar distrbusi frekuensi.

\section{HASIL DAN PEMBAHASAN}

Penelitian dilakukan di SMPN 1 Lemahsugih yang terletak di Jl. Raya Lemahsugih No.702 Kecamatan Lemahsugih Kabupaten Majalengka. Jumlah guru sebanyak 22 orang tetap. Responden pada penelitian ini adalah siswa kelas VII A yang berjumlah 33 orang. Hasil mengenai kusioner pengetahuan kesehatan gigi dan mulut adalah sebagai berikut:

Tabel 1. Distribusi Frekuensi Pengetahuan Kesehatan Gigi dan Mulut

\begin{tabular}{cccc}
\hline No & Kategori & Jumlah & Persentase (\%) \\
\hline $\mathbf{1}$ & Baik & 9 & 27.2 \\
\hline $\mathbf{2}$ & Sedang & 24 & 72.8 \\
\hline $\mathbf{3}$ & Kurang & 0 & 0 \\
\hline & Jumlah & $\mathbf{3 3}$ & $\mathbf{1 0 0}$ \\
\hline
\end{tabular}

Kategori pengetahuan baik dengan rentan nilai (10-15) sebanyak 9 orang (27.2\%), kategori pengetahuan sedang dengan rentang nilai (6-9) sebanyak 24 orang (72.8\%), dan untuk kategori pengetahuan kurang dengan rentan nilai (1-5) sebanyak 0 orang (0\%), dari penjelasan diatas kategori yang mendominasi adalah kategori pengetahuan sedang dengan rentang nilai (6-9) sebanyak 24 orang (72.8\%). Kemudian dilakukan pengukuran untuk 33 orang siswa hasil $O H I-S$ nya adalah sebagai berikut 
Tabel 2. Distribusi Frekuensi Hasil pengukuran $\mathrm{OHI}-\mathrm{S}$

\begin{tabular}{cccc}
\hline No & Kriteria $\boldsymbol{O H I - S}$ & Jumlah & Persentase (\%) \\
\hline 1 & Baik & 9 & 27.3 \\
\hline 2 & Sedang & 16 & 48.5 \\
\hline 3 & Buruk & 8 & 24.2 \\
\hline & Jumlah & 33 & 100 \\
\hline
\end{tabular}

Hasil pemeriksaan Oral Hygiene Index Simplified (OHI-S) yang telah dilakukan pada siswa kelas VII SMPN 1 Lemahsugih didapatkan hasil kategori Oral Hygiene Index Simplified baik dengan rentan nilai $(0,0-1,2)$ sebanyak 9 orang $(27.3 \%)$, kategori Oral Hygiene Index Simplified sedang dengan rentan nilai (1.3 - 3.0) sebanyak 16 orang (48.5\%), dan untuk kategori Oral Hygiene Index Simplified buruk (3.1 - 6.0) sebanyak 8 orang $(24.2 \%)$, dari penjelasan diatas kriteria yang paling mendominasi adalah kategori Oral Hygiene Index Simplified sedang dengan rentan nilai (1.3 - 3.0) sebanyak 16 orang $(48.5 \%)$. Kemudian dibuat tabel perpaduan antara pengetahuan kesehatan dengan OHIS sebagai berikut:

Tabel 3. Gambaran tingkat pengetahuan kesehatan gigi dan mulut dengan indeks $\mathrm{OHI}-\mathrm{S}$

\begin{tabular}{ccccccc}
\hline $\mathbf{N o}$ & Pengetahuan & $\mathbf{N}$ & $\mathbf{\%}$ & Kriteria & $\mathbf{N}$ & $\boldsymbol{\%}$ \\
\hline $\mathbf{1}$ & Baik & 9 & 27.2 & Baik & 9 & 27.3 \\
\hline $\mathbf{2}$ & Sedang & 24 & 72.8 & Sedang & 16 & 48.5 \\
\hline $\mathbf{3}$ & Buruk & 0 & 0 & Buruk & 8 & 24.2 \\
\hline & Jumlah & $\mathbf{3 3}$ & $\mathbf{1 0 0}$ & & $\mathbf{3 3}$ & $\mathbf{1 0 0}$ \\
\hline
\end{tabular}

Gambaran antara tingkat pengetahuan kesehatan gigi dan mulut terhadap Indeks $O H I$ $S$ pada siswa kelas VII SMPN 1 Lemahsugih. Pada tingkat pengetahuan baik 9 orang (27.2\%) dengan kriteria $O H I-S$ baik 9 orang (27.3\%), tingkat pengetahuan sedang 24 orang $(27.8 \%)$, dengan kriteria $O H I-S$ sedang 16 orang $(48.5 \%)$, dan tingkat pengetahuan buruk 0 $(0 \%)$ dengan kriteria $O H I-S$ buruk 8 orang $(24 . \%)$. Berdasarkan data diatas tingkat pengetahaun dan $O H I-S$ yang paling mendominasi adalah tingkat pengetahuan sedang 24 orang $(27.8 \%)$, dengan kriteria $O H I-S$ sedang 16 orang $(48.5 \%)$,

Hasil penelitian tentang gambaran pengetahuan tentang kesehatan gigi dan mulut terbukti memberikan gambaran. Berdasarkan penelitian dengan penyebaran kuesioner dihasilkan dari 33 siswa kelas VII A mempunyai rata-rata pengetahuan kesehatan gigi dan mulut sedang dan status kebersihan gigi sedang. Hasil penelitian ini didukung dari penelitian yang telah dilakukan oleh Kowela (2012). Hasil penelitian yang dilakukan oleh Kowela (2012) hampir sama dengan hasil penelitian yang dilakukan di SMPN 1 
Lemahsugih Majalengka, bahwa tingkat pengetahuan kesehatan gigi dan mulut dan status kesehatan gigi dan mulut mempunyai kategori rata-rata sedang.

Tingkat kebersihan gigi dan mulut dapat dipengaruhi oleh faktor sosial ekonomi, latar belakang pendidikan juga kebiasaan-kebiasaan yang ditanamkan dalam keluarganya masing-masing sejak masa anak-anak, sebagaimana penelitian yang telah dilakukan oleh Sari (2001), pemeliharaan kebersihan gigi dan mulut dipengaruhi oleh kebiasaankebiasaan yang telah ditanamkan sejak masa anak-anak pada lingkungan keluarganya, terutama mengenai pentingnya pengetahuan kebersihan gigi dan mulut.

Pengetahuan tentang kebersihan gigi dan mulut sangat penting untuk terbentuknya tindakan dalam menjaga kebersihan gigi dan mulut. Menjaga kebersihan gigi dan mulut dilakukan untuk mencegah penyakit gigi dan mulut, meningkatkan daya tahan tubuh. Menjaga kebersihan gigi dan mulut pada usia sekolah merupakan salah satu cara dalam meningkatkan kesehatan gigi dan mulut pada usia dini, kesehatan gigi adalah bagian integral dari kesehatan umum, sehingga perlu bagi kesehatan gigi untuk senantiasa meningkatkan kemampuan sesuai dengan perkembangan kesehatan pada umumnya. Penyebab timbulnya masalah kesehatan gigi dan mulut pada masyarakat salah satunya adalah faktor perilaku atau sikap mengabaikan kebersihan gigi dan mulut (Notoatmodjo, 2010 Cit.Fankari 2004 ) pernyataan tersebut dilandasi oleh kurangnya pengetahuan akan pentingnya pemeliharaan kesehatan gigi dan mulut.

\section{KESIMPULAN}

Berdasarkan hasil penelitian tentang "Gambaran pengetahuan tentang kesehatan gigi dan mulut dengan status kebersihan gigi dan mulut pada siswa kelas VII SMPN 1 Lemahsugih Kabupaten Majalengka Tahun 2015", maka dapat disimpulakn sebagai berikut : 1) Tingkat pengetahuan tentang kesehatan gigi dan mulut siswa kelas VII A SMPN 1 Lemahsugih Kabupaten Majalengka, yang mendominasi adalah kategori pengetahuan kategori pengetahuan sedang dengan rentan nilai (6-9) sebanyak 24 orang (72.8\%), 2) Hasil pemeriksaan Oral Hygiene Index Simplified (OHI-S) siswa kelas VII SMPN 1 Lemahsugih Kabupaten Majalengka, yang mendominasi adalah kategori sedang dengan rentan nilai $(1.3-3.0)$ sebanyak 16 orang $(48.5 \%)$,

\section{DAFTAR PUSTAKA}

Ajja, A. 2013. Karakteristik Anak Usia SMP.

https://id.scribd.com/doc/169299304/Karakteristik-Anak-Usia-SMP (diakses pada tanggal 25 Januari 2015)

Dentika Dental Journal Kedokteran, 2002. Efek Penyuluhan dalam Penurunan Indeks Plak Pada Murid SD Kelas IV dan V di SD, Medan, Vol 2 No 1, Jakarta.

Departemen Kesehatan, R.I., 1990, Profil Kesehatan Gigi dan Mulut di Indonesia pada Pelita ke-VI. Jakarta : Direktorat Jendral Pelayanan Medik.

Fankari, F. 2004. Pengaruh Penyuluhan dengan Metode Simulasi dan Demontrasi Terhadap Perubahan Perilaku Menjaga Kesehatan Gigi dan Mulut Anak Sekolah Dasar. KTI DIV Perawat Pendidik UGM.

Fitriani, S. 2011. Promosi Kesehatan. Yogyakarta; Graha Ilmu.

Herijulianti, E., Indriani, T.S., Artini, S. 2002. Pendidikan Kesehatan Gigi. Jakarta : EGC. 
Kompas, 2007. Metoda Pelayanan Kesehatan Gigi Pada Murid SD dalam Rangka Peningkatan Pemerataan Pelayanan.

www.Badan,Litbang.Depkes.id.Com. diakses tanggal 22 Februari 2015

Kowela. W.T, 2012. Gambaran Tingkat Pengetahuan Pemeliharaan Kesehatan Gigi dan Mulut Dengan Indeks OHI-S pada Mahasiswa Tingkat 1 Jurusan Keperawatan Gigi Politeknik Kesehatan Tasikmalaya. Kasikmalaya

Margareta, S. 2012. 101 Tips dan Terapi Alami agar Gigi Putih dan Sehat. Yogyakarta: Pustaka Cerdas.

Miko, H. and Suminar, L.R., 2017. Pengaruh Penyuluhan Media Tiga Dimensi Pada Pengguna Siwak Modifikasi Terhadap Kebersihan Gigi Dan Mulut Pada Santri Di Pesantren Al-Kautsar Kabupaten Kuningan. Indonesian Oral Health Journal, 2(1).

Notoatmodjo, S. 2003. Pendidikan dan Perilaku Kesehatan. Jakarta : Rineka Cipta.

Notoatmodjo, S. 2010. Ilmu Perilaku Kesehatan. Jakarta : Rineka Cipta

Notoatmodjo, S. 2007. Promosi Kesehatan dan Ilmu Perilaku. Jakarta : Rineka Cipta.

Nursalam, Pariani, 2001. Pendekatan Praktis Metodologi Riset Keperawatan, Jakarta : Salemba Medika.

Nursalam, 2009. Konsep dan Penerapan Metodologi Penelitian Ilmu Keperawatan. Jakarta : Salemba Medika.

PRO HEALTH, 2006. Kesehatan Gigi dan Mulut. http://bz.blogfam.com (Diakses 29 juni 2015).

PRO HEALTH, 2010. Kesehatan Gigi dan Mulut.

http://wartawarga.gunadarma.ac.id (Diakses 25 februari 2015)

Putri, M. H., Herijulianti, E dan Nurjanah, N. 2010. Ilmu Pencegahan Penyakit Jaringan Keras dan Jaringan Pendukung Gigi. Jakarta: EGC.

Ramadhan, A.G., 2010, Serba Serbi Kesehatan Gigi dan Mulut. Jakarta: Bukune

Setyosari, P., 2010.Metode Penelitian Pendidikan dan Pengembangan. Jakarta: Kencana.

Soekanto, S. 2010. Sosiologi Suatu Pengantar. Jakarta: Kelapa Gading Permai.

Suliha, U., Herawani, Sumiati, Resnayani, Y., 2002. Pendidikan Kesehatan Dalam Keperawatan. Jakarta: EGC.

Sunaryo, 2004, Psikologi Untuk Keperawatan, Jakarta : EGC.

Susanto, G.W., 2011, Terapi Gusi, Jakarta : Erlangga. 
Home page: http://ejurnal.poltekkestasikmalaya.ac.id/index.php/jikg

Yusuf, S. 2014. Psikologi Perkembangan Anak dan Remaja. Bandung : Remaja Rosdakarya Offset.

Zulkifi. 2005. Psikologi Perkembangan. Bandung: Remaja Rosdakarya Offset. 